\title{
Morphometry of the Cervical Vertebral Pedicles as a Guide for Transpedicular Screw Fixation
}

\author{
Gulgun KAYAliOglu, Mete ERTURK, Tuncay VAROL*, and Enis CEZAYIRLI* \\ Department of Anatomy, Ege University Faculty of Medicine, Bornova, Izmir, Turkey; \\ ${ }^{*}$ Department of Anatomy, Celal Bayar University Faculty of Medicine, Manisa, Turkey
}

\begin{abstract}
Anatomical measurements of the cervical pedicle in a large series of human cervical vertebrae from 48 individuals were obtained to reduce the incidence and severity of complications caused by transpedicular screw placement. The greatest pedicle length was at C-3 and the greatest pedicle width was at C-6. Pedicle width and lateral mass thickness gradually increased from C-3 to C-6. Pedicle height and interpedicular distance increased from C-3 to C-5, and decreased slightly at C-6. The lateral masspedicle length was greatest at $C-4$. The present study found right-left differences for the pedicle-spinous process distance at $C-6(p<0.05)$. Pedicle width and height were smaller than those reported in earlier studies, especially at C-3 and C-4, whereas the increasing pedicle widths at C-5 and C-6 were appropriate for pedicle screw fixation.
\end{abstract}

Key words: cervical pedicle, anatomy, right-left difference, morphometry

\section{Introduction}

Transpedicular screw fixation is a complicated surgical procedure that is widely used for the treatment of spinal instabilities. This procedure was introduced for the treatment of unstable cervical spine after traumatic lesions of the middle and lower cervical spine, but is also particularly important for simultaneous posterior decompression and reconstruction in the cervical spine. ${ }^{2,3)}$ The indications have now been extended to spinal instabilities resulting from neoplasms, failed anterior fusion, degenerative conditions such as rheumatoid arthritis, cervical spondylotic myelopathy, and ankylosing spondylitis, infections, extensive laminectomies, and osteotomy and postlaminectomy kyphosis reconstructions. , $^{1,16,20)}$

The cervical spinal pedicles are very strong structural elements of the vertebrae and offer the strongest point of attachment to the spine. Transpedicular screw fixation is especially useful if the posterior spinal elements (spinous processes, lamina) are unsuitable for fixation by hook or wire constructs. ${ }^{6)}$ This technique provides the greatest stability to the cervical spine, with reduced likelihood of hardware loosening, compared to anterior plating, lateral

Received January 11, 2006; Accepted October 25, 2006 mass screw and plate fixation, and posterior wiring techniques. ${ }^{11,14,16,22)}$ Transpedicular screw fixation is also biomechanically superior to these techniques. ${ }^{15)}$ However, this procedure carries the risk of damaging important neurovascular structures neighboring the pedicle, such as the spinal cord, nerve roots, facet joints, and the vertebral artery. ${ }^{13)}$

This anatomic study of a large series of human dry bone specimens was undertaken to obtain detailed anatomical data of the cervical pedicle to reduce the incidence and severity of complications caused by transpedicular screw placement.

\section{Material and Methods}

Forty-eight adult dried bone cervical spines from C-3 to C-6 (192 vertebrae) were obtained from the collection of the Department of Anatomy, Ege University Faculty of Medicine. Only specimens without signs of infectious, neoplastic, traumatic, or degenerative diseases, and without congenital or developmental spinal malformation were used. All measurements were taken bilaterally on C-3 to C-6 vertebrae using digital stainless steel calipers with $0.1 \mathrm{~mm}$ accuracy. Eight linear parameters of the cervical pedicle were measured as follows (Figs. 1 and 2): 1) pedicle length, the distance between the vertebral body pedicle junction and the lateral mass; 2) pedicle width, the medial-lateral diameter of the pedicle 
Table 1 Linear measurements of the C3-6 vertebrae

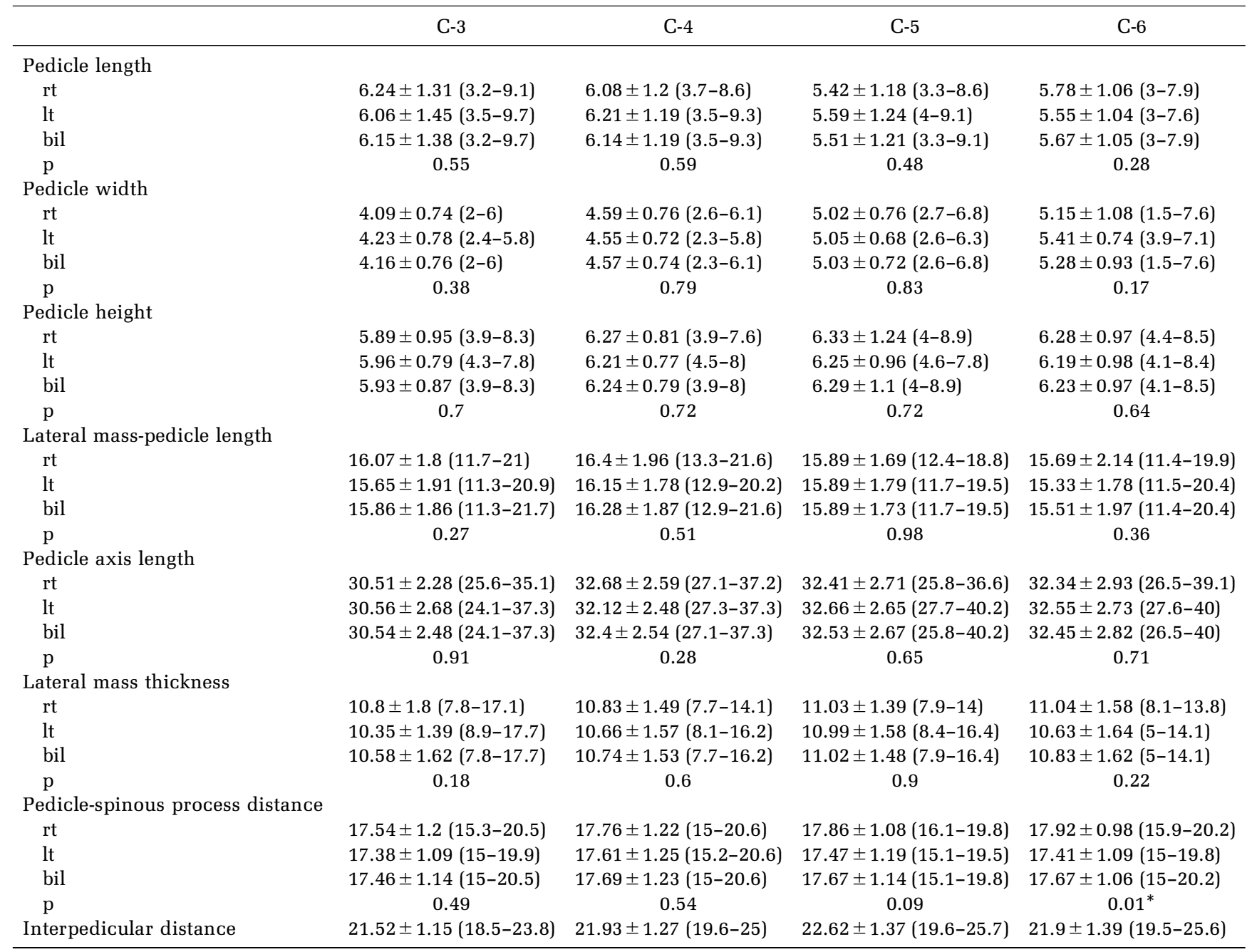

Values are mean \pm standard deviation (range), mm. ${ }^{*} \mathrm{p}<0.05$

isthmus at the narrowest point; 3) pedicle height, the superior-inferior diameter of the pedicle isthmus at the narrowest point; 4) lateral mass pedicle length, the distance from the posterior point of the pedicle axis projection on the lateral mass to the vertebral body; 5) pedicle axis length, the distance from the posterior point of the lateral mass to the anterior margin of the vertebral body through the pedicle axis; 6) lateral mass thickness; 7) pedicle-spinous process distance; and 8) interpedicular distance. Measurement of some of these parameters required two imaginary lines drawn along the pedicle axis (pedicle axis line, abcd) and the pedicle isthmus (pedicle isthmus line, ef) (Fig. 1).

Mean and standard deviation, and ranges were obtained for each parameter, and Student's t-test was used for statistical analysis of right-left differences.

\section{Results}

Table 1 shows the values for all measurements in the C-3 to C-6 vertebrae. The greatest pedicle length was at C-3 and the greatest pedicle width was at C-6. Pedicle width and lateral mass thickness gradually increased from C-3 to C-6. Pedicle height and interpedicular distance increased from C-3 to C-5, and decreased slightly at C-6. The lateral masspedicle length was greatest at C-4. Photographs and axial computed tomography scans of C-3 and C-6 vertebrae with a very thin pedicle on the right side are shown in Figs. 3 and 4, respectively.

The range values in Table 1 show that there was considerable variation among the specimens. Investigation of the right-left differences showed no statistically significant differences in most of the parameters, except for the pedicle-spinous process 
Table 2 Comparison of present and previous measurements of pedicle dimensions

\begin{tabular}{|c|c|c|c|c|c|c|}
\hline \multirow{2}{*}{ Author (Year) } & \multicolumn{3}{|c|}{ C-3 } & \multicolumn{3}{|c|}{ C-4 } \\
\hline & Length & Width & Height & Length & Width & Height \\
\hline $\begin{array}{c}\text { Panjabi et al. } \\
(1991)^{19)}\end{array}$ & ND & $5.6 \pm 0.5$ & $7.4 \pm 0.5$ & ND & $5.4 \pm 0.6$ & $7.4 \pm 0.5$ \\
\hline $\begin{array}{l}\text { Stanescu et al. } \\
(1994)^{23)}\end{array}$ & ND & ND & ND & ND & ND & ND \\
\hline $\begin{array}{l}\text { Ebraheim et al. } \\
\left.(1997)^{7}\right)\end{array}$ & ND & $4.7 \pm 0.9$ & $5.8 \pm 0.7$ & ND & $4.7 \pm 0.7$ & $6.6 \pm 0.7$ \\
\hline $\begin{array}{l}\text { Jones et al. } \\
(1997)^{11)}\end{array}$ & ND & 4.8 & 7.4 & ND & 5.2 & 8.0 \\
\hline $\begin{array}{l}\text { Karaikovic et al. } \\
(1997)^{12)}\end{array}$ & ND & $4.9 \pm 0.9$ & $6.8 \pm 0.9$ & ND & $5.0 \pm 0.8$ & $7.3 \pm 1.0$ \\
\hline $\begin{array}{l}\text { Xu et al. } \\
(1999)^{25)}\end{array}$ & ND & $5.1 \pm 0.9$ & $6.4 \pm 0.8$ & ND & $4.7 \pm 0.7$ & $6.5 \pm 1.0$ \\
\hline $\begin{array}{l}\text { Ugur et al. } \\
(2000)^{24)}\end{array}$ & ND & $4.9 \pm 0.5$ & $6.3 \pm 0.5$ & ND & $5.2 \pm 0.6$ & $6.5 \pm 0.5$ \\
\hline $\begin{array}{l}\text { Panjabi et al. } \\
(2000)^{20)}\end{array}$ & ND & $4.3 \pm 0.9$ & $6.7 \pm 1.2$ & ND & $4.4 \pm 0.7$ & $7.1 \pm 0.8$ \\
\hline $\begin{array}{l}\text { Bozbuga et al. } \\
(2004)^{5)}\end{array}$ & $5.3 \pm 0.6$ & $4.5 \pm 0.5$ & $6.9 \pm 0.9$ & $5.4 \pm 0.6$ & $4.4 \pm 0.6$ & $6.7 \pm 0.7$ \\
\hline Present study & $6.15 \pm 1.38$ & $4.16 \pm 0.76$ & $5.93 \pm 0.87$ & $6.14 \pm 1.19$ & $4.57 \pm 0.74$ & $6.24 \pm 0.79$ \\
\hline
\end{tabular}

Values are mean \pm standard deviation, mm. ND: not detected.

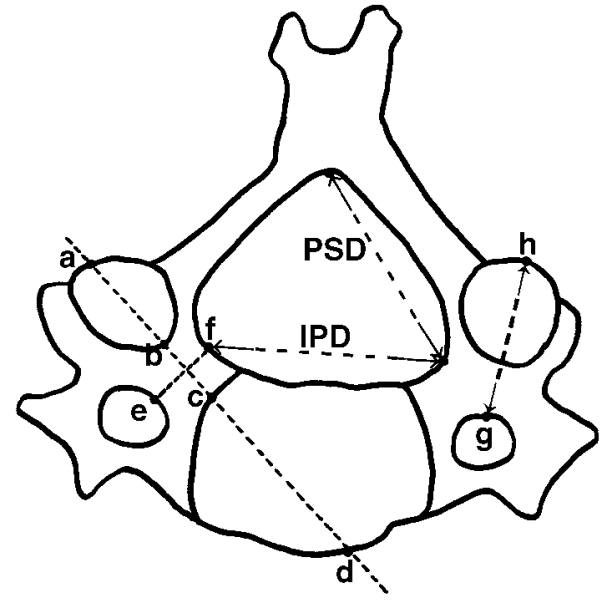

distance at C-6 ( $p<0.05)$. However, the right-left difference of the pedicle size, as shown in Fig. 4, may be important from a clinical standpoint.

\section{Discussion}

The intraoperative and postoperative complications of transpedicular screw fixation include unrecognized screw misplacement, fracturing of the pedicle during screw insertion, iatrogenic cerebrospinal fluid leak, and postoperative deep infection and transient neurapraxia. ${ }^{8)}$ Cortical wall violations can damage the spinal cord, nerve root, facet joints, and vertebral arteries. ${ }^{2,211}$ The incidence of these violations is $30.3 \%$ to $87.5 \%$ in anatomical studies. $4,7,10,18)$
Fig. 1 Linear measurements of the cervical pedicle and reference points. a: the most posterior aspect of the facet along the pedicle axis line, b: the most posterior aspect of the pedicle along the pedicle axis line, c: the most posterior aspect of the vertebral body along the extension of the pedicle axis line, d: the most anterior aspect of the vertebral body along the extension of the pedicle axis line, e: the most lateral point of the pedicle isthmus along the pedicle isthmus line, $\mathrm{f}$ : the most medial point of the pedicle isthmus along the pedicle isthmus line, g: the most posterior aspect of the transverse foramen, h: the most posterior aspect of the facet, ac: lateral mass-pedicle length, ad: pedicle axis length, bc: pedicle length, ef: pedicle width, gh: lateral mass thickness, IPD: interpedicular distance, PSD: pedicle-spinous process distance.

The risk increases in the cephalad direction of the cervical spine. ${ }^{17)}$

Anatomical studies on human cadavers provide information about the cervical spine transpedicle anatomy including landmarks for screw insertion and determination of screw size..$^{5,7,11,12,19,20,23-25)}$ The entrance point for screw insertion is recommended to be the middle of the articular mass, $3 \mathrm{~mm}$ beneath the superior facet, and at a medial angle of $45^{\circ}$ in the 
Table 2, continued

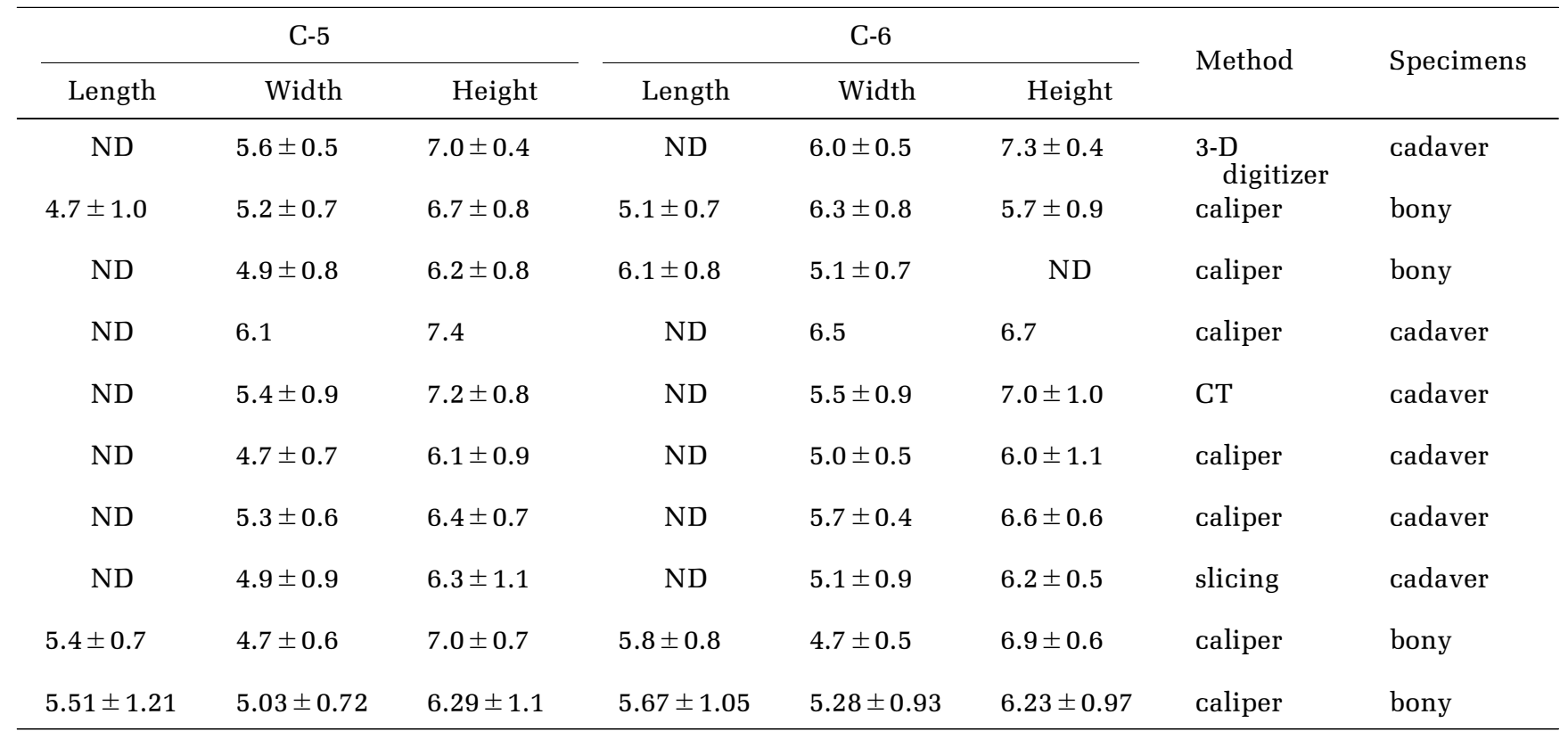

3-D: three-dimensional, CT: computed tomography.

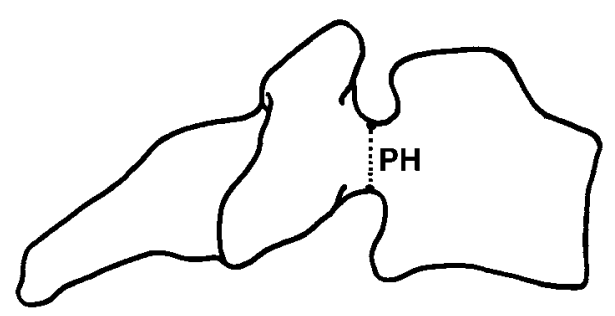

Fig. 2 Linear measurements of the cervical pedicle. PH: pedicle height.

transverse plane of C-3 to C-7. ${ }^{10)}$ Other studies propose the same entry point but $1 \mathrm{~mm}$ inferior to the caudal edge of the facet joint in the midline of the lateral mass. ${ }^{1,2)} \mathrm{A}$ high variability in cervical pedicle dimensions is reported. Table 2 compares our results with previous studies. ${ }^{5,7,11,12,19,20,23-25)}$

A pedicle diameter smaller than $4.5 \mathrm{~mm}$ carries the risk of pedicle wall violation and important neurovascular structure damage. ${ }^{16)}$ Our study of pedicle width and height found smaller values than those reported in earlier studies. ${ }^{5,7,11,12,19,20,23-25)}$ Based on our results, we suggest that the C-3 and C-4 vertebrae have more risk for pedicle screw fixation, whereas the C-5 and C-6 have greater pedicle width appropriate for screw fixation.

Previous studies did not analyze right-left differences in cervical pedicle morphometry, except in two studies which observed no significant right-left differences. ${ }^{5,23)}$ In contrast, the present study found
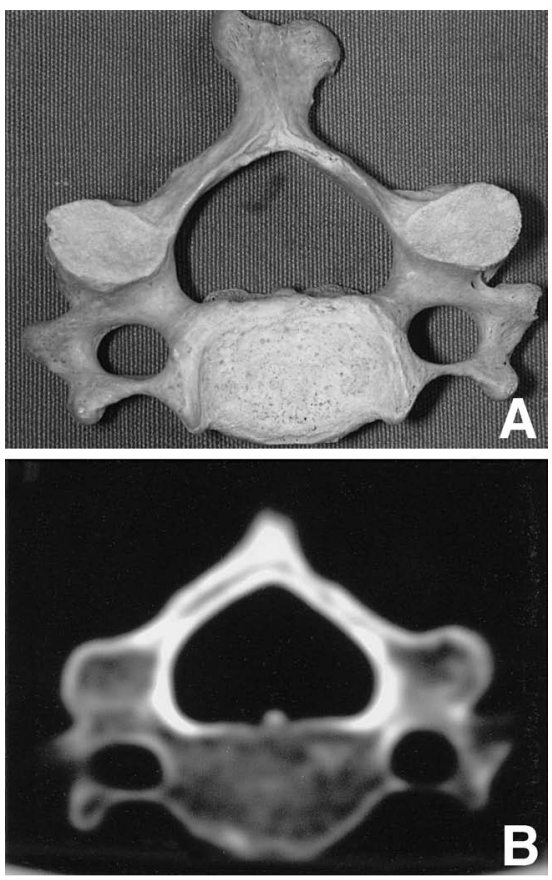

Fig. 3 Photograph (A) and axial computed tomography scan (B) of the C-3 vertebra.

right-left differences for the pedicle-spinous process distance at C-6 (Table 1).

Anatomic variations in the size of the cervical pedicles limit the application of pedicle screws. Large or long pedicle screws may result in pedicle 

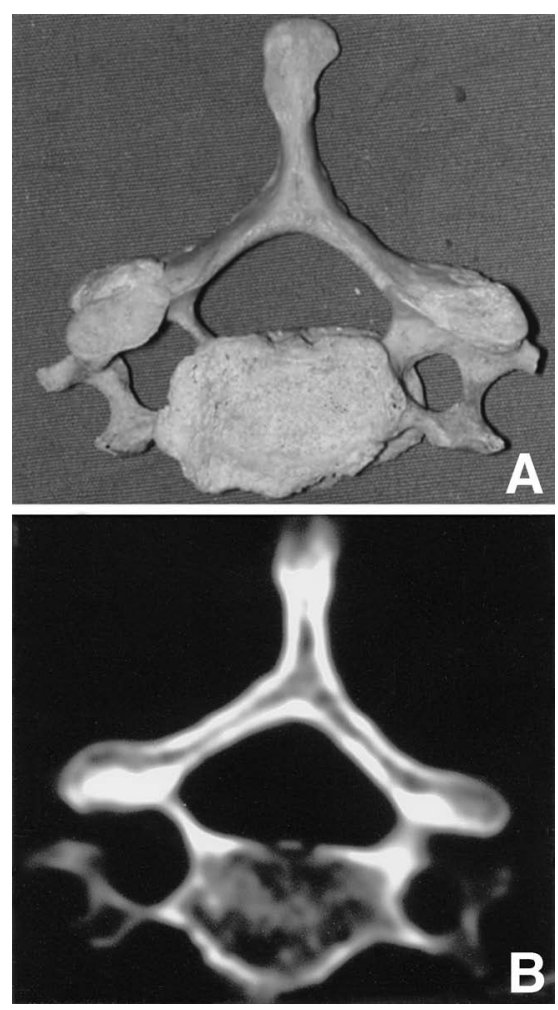

Fig. 4 Photograph (A) and axial computed tomography scan (B) of the C-6 vertebra with a very thin pedicle on the right side.

fracture or damage of important neurovascular structures. Previous studies suggest the use of screws with diameters of $2.7 \mathrm{~mm},{ }^{11)} 3 \mathrm{~mm},{ }^{18)} 3.5$ $\mathrm{mm},{ }^{9)} 4 \mathrm{~mm},{ }^{10)} 4.5 \mathrm{~mm},{ }^{1)}$ and $5.5 \mathrm{~mm} .{ }^{14)}$ Our measurements of smaller pedicle width and height suggest smaller diameter screws. In addition, the relative increase in pedicle width and height, and the decrease in pedicle length from cephalad to caudad are important for choosing the appropriate screw size.

Preoperative radiography (bilateral oblique views), computed tomography, magnetic resonance imaging, intraoperative fluoroscopy, and stereotactic computer-assisted guidance systems are all valuable for assessing the individual variations in the critical pedicle dimensions, and for the determination of the appropriate screw size and optimum approach. . $, 7,12)$

The present results show high individual variations in many parameters that highlight the risk of damaging important neurovascular structures during transpedicular screw fixation, in particular the small values of the pedicle dimensions compared to previous studies, the cephalad to caudad variation, and significant right-left differences in the pedicle-spinous process distance at C-6.

\section{References}

1) Abumi $\mathrm{K}$, Itoh $\mathrm{H}$, Taneichi $\mathrm{H}$, Kaneda $\mathrm{K}$ : Transpedicular screw fixation for traumatic lesions of the middle and lower cervical spine. J Spinal Disord 7: 19-28, 1994

2) Abumi K, Kaneda K: Pedicle screw fixation for nontraumatic lesions of the cervical spine. Spine 22: 1853-1863, 1997

3) Abumi K, Kaneda K, Shono Y, Fujiya M: One-stage posterior decompression and reconstruction of the cervical spine by using pedicle screw fixation systems. J Neurosurg 90: 19-26, 1999

4) An HS, Gordin R, Renner K: Anatomic considerations for plate-screw fixation of the cervical spine. Spine 16: S548-S551, 1991

5) Bozbuga M, Ozturk A, Ari Z, Sahinoglu K, Bayraktar B, Cecen A: Morphometric evaluation of subaxial cervical vertebrae for surgical application of transpedicular screw fixation. Spine 29: 1876-1880, 2004

6) Coe JD, Warden KE, Sutterlin CE III, McAfee PC: Biomechanical evaluation of cervical stabilization methods in a human cadaveric model. Spine 14: 1122-1131, 1989

7) Ebraheim NA, $\mathrm{Xu} \mathrm{R}$, Knight $\mathrm{T}$, Yeasting RA: Morphometric evaluation of lower cervical pedicle and its projection. Spine 22: 1-5, 1997

8) Esses SI, Sachs BL, Dreyzin V: Complications associated with the technique of pedicle screw fixation. A selected survey of ABS members. Spine 18: 2231-2239, 1993

9) Heller JG, Estes BT, Zaouali M, Diop A: Biomechanical study of screws in the lateral masses: variables affecting pull-out resistance. J Bone Joint Surg Am 78: 1315-1321, 1996

10) Jeanneret B, Gebhard JS, Magerl F: Transpedicular screw fixation of articular mass fracture-separation: Results of an anatomical study and operative technique. J Spinal Disord 7: 222-229, 1994

11) Jones EL, Heller JG, Silcox DH, Hutton WC: Cervical pedicle screws versus lateral mass screws: Anatomic feasibility and biomechanical comparison. Spine 22: 977-982, 1997

12) Karaikovic EE, Daubs MD, Madsen RW, Gaines RW Jr: Morphologic characteristics of human cervical pedicle. Spine 22: 493-500, 1997

13) Karaikovic EE, Kunakornsawat S, Daubs MD, Madsen RW, Gaines RW Jr: Surgical anatomy of the cervical pedicles: Landmarks for posterior cervical pedicle entrance localization. J Spinal Disord 13: 63-72, 2000

14) Kotani Y, Cunningham BW, Abumi K, McAfee PC: Biomechanical analysis of cervical stabilization systems: An assessment of transpedicular screw fixation in the cervical spine. Spine 19: 2529-2539, 1994

15) Ludwig SC, Kramer DL, Balderston RA, Vaccaro AR, Foley KF, Albert TJ: Placement of pedicle screws in the human cadaveric cervical spine. Comparative 
accuracy of three techniques. Spine 25: 1655-1667, 2000

16) Ludwig SC, Kramer DL, Vaccaro AR, Albert TJ: Transpedicular screw fixation of the cervical spine. Clin Orthop Relat Res 359: 77-88, 1999

17) Merola AA, Castro BA, Alongi PR, Mathur S, Brkaric M, Vigna F, Riina JP, Gorup J, Haher TR: Anatomic considerations for standard and modified techniques of cervical lateral mass screw placement. Spine J 2: 430-435, 2002

18) Miller RM, Ebraheim NA, $\mathrm{Xu} R$, Yeasting RA: Anatomic consideration of transpedicular screw placement in the cervical spine: An analysis of two approaches. Spine 21: 2317-2322, 1996

19) Panjabi MM, Duranceau J, Goel V, Oxland T, Takata $\mathrm{K}$ : Cervical human vertebrae: quantitative threedimensional anatomy of the middle and lower regions. Spine 16: 861-869, 1991

20) Panjabi MM, Shin EK, Chen NC, Wang JL: Internal morphology of human cervical pedicles. Spine 25: 1197-1205, 2000

21) Roy-Camille R, Mazel C, Saillant G, Benazet JP: Rationale and techniques of internal fixation in trauma of the cervical spine, in Errico T, Bauer RD, Waugh T (eds): Spinal Trauma. Philadelphia, Lippincott, 1991, pp 163-191

22) Shin EK, Panjabi MM, Chen NC, Wang JL: The anatomic variability of human cervical pedicles: considerations for transpedicular screw fixation in the middle and lower cervical spine. Eur Spine J 9: 61-66, 2000

23) Stanescu S, Ebraheim NA, Yeasting R, Bailey AS, Jackson WT: Morphometric evaluation of the cervico-thoracic junction. Spine 19: 2082-2088, 1994

24) Ugur HC, Attar A, Uz A, Tekdemir I, Egemen N, Caglar S, Genc Y: Surgical anatomic evaluation of the cervical pedicle and adjacent neural structures. Neurosurgery 47: 1162-1169, 2000

25) Xu R, Kang A, Ebraheim NA, Yeasting RA: Anatomic relation between the cervical pedicle and the adjacent neural structures. Spine 24: 451-454, 1999

Address reprint requests to: Gulgun Kayalioglu, M.D., Department of Anatomy, Ege University Faculty of Medicine, TR-35100, Bornova, Izmir, Turkey. e-mail: gulgun.kayalioglu@ege.edu.tr kayali@rocketmail.com

\section{Commentary}

Posterior decompressive surgery, such as laminectomy or laminoplasty, has been performed for patients with cervical myelopathy. When such patients show spinal instability, posterior fixation has been simultaneously planned. Due to lack of laminae and spinous processes, lateral mass plating or pedicle screw fixation method can be applied for these patients. These posterior fixation methods can also be applied for patients with cervical spine trauma or metastatic tumors with cervical instability. Although the pedicle screw fixation method is biomechanically superior to the lateral mass plating method, this procedure has a high incidence of surgical complications, such as injuries of the dura mater, nerve roots, spinal cord and vertebral artery. In the present paper, Kayalioglu et al. studied morphometry of the cervical vertebral pedicles using human dry bone specimens. The authors measured eight parameters in forty-eight adult dried bone cervical specimens from C-3 to C-6 (192 vertebrae). The authors reported that pedicle width and height were smaller than those reported in earlier studies, especially at C-3 and C-4, whereas the pedicle width increased at $C-5$ and $C-6$. They suggested that there is greater risk for pedicle fractures at the C-3 and C-4 levels, whereas the C-5 and C-6 levels have greater pedicle width appropriate for screw fixation. They also described the high individual variation in many parameters and right-left difference. Based upon the authors' description, we must meticulously examine the shape of the pedicles by CT scan preoperatively, if pedicle screw fixation method is planned, especially at the higher cervical level at $\mathrm{C}-3$ and C-4. The knowledge obtained by the present study is useful in the cervical pedicle screw fixation procedure.

Junya HanaKita, M.D. Spinal Disorders Center Fujieda Heisei Memorial Hospital Shizuoka, Japan

The cervical spine has been instrumented for fusion in many ways. Various techniques include the use of wires, hooks, rods, blocks, lateral mass screws, and more recently, pedicle screws. In this work the authors have painstakingly manually measured cervical spine specimens from 48 cadavers to provide useful anatomic parameters for spine surgeons. Of special import is their measurement of the cervical pedicle width, length and height. These are practical dimensions that determine what size cervical pedicle screw a surgeon could place while avoiding breach, break-out, and adjacent structure injury. The work is thorough, and the results are certainly useful for considering novel techniques.

Recently, there has been increased interest in fully utilizing the pedicle of the cervical spine for fusion. For example, in 1997 Abumi and Kaneda published work on the use of cervical pedicle screws for fixation in non-traumatic injury.1) Using morphometric dimensions obtained from CT scans, Reinhold et al. in 2007 explore cervical fixation techniques. ${ }^{4)}$ Recent- 
ly, there has been interest in using image guided techniques to help guide and improve pedicle screw fixation. ${ }^{2,3)}$ As more spine surgeons consider these fixation techniques, works such as this one become increasingly important.

Certainly every surgeon must carefully review the preoperative films to judge each patient individually in choosing a fixation technique. Overall, this article is well presented and will serve to augment our knowledge of the anatomy of the human spine.

\section{References}

1) Abumi K, Kaneda K: Pedicle screw fixation for nontraumatic lesions of the cervical spine. Spine 22: 1853-1863, 1997

2) Kowalski JM, Ludwig SC, Hutton WC, Heller JG: Cervical spine pedicle screws: a biomechanical comparison of two insertion techniques. Spine 25: 2865-2867, 2000

3) Ludwig SC, Kowalski JM, Edwards CC 2nd, Heller JG: Cervical pedicle screws: comparative accuracy of two insertion techniques. Spine 25: 2675-2681, 2000

4) Reinhold M, Magerl F, Rieger M, Blauth M: Cervical pedicle screw placement: feasibility and accuracy of two new insertion techniques based on morphometric data. Eur Spine J 16: 47-56, 2007

Howard B. Levene, M.D., Ph.D. and Christopher M. LofTUs, M.D., D.H.C. (Hon.), F.A.C.S. Department of Neurosurgery Temple University Hospital Philadelphia, Pennsylvania, U.S.A.

This is an important anatomical work at a time when surgical fixation for instable spine develops increasing indications. The authors give precise morphometric description, showing that pedicles are particularly wide at C-5 and C-6, which is appropriate for screw fixation. The authors also stress the frequent right-left asymmetry, with eventuality of very thin pedicle. The high incidence of individual variations makes computed tomography scanning mandatory before surgery. Morphometric data have to be harvested and used for navigation when available.

Marc P. Sindou, M.D., D.Sc.

University of Lyon

Lyon, France 